\author{
Journal of International Business Research and \\ Marketing \\ Volume 4, Issue 2, 2019 \\ journal homepage: www.researchleap.com
}

\title{
The Importance of Social Media and Digital Marketing to Attract Millennials’ Behavior as a Consumer
}

\section{Sarah Silvia}

Master Degree of Communication, London School of Public Relations Jakarta, Marketing Communication, Indonesia

\begin{tabular}{|c|c|}
\hline & ABSTRACT \\
\hline $\begin{array}{l}2019 \text { Research Leap/Inovatus Services Ltd. } \\
\text { All rights reserved. } \\
\text { DOI: } 10.18775 / \text { jibrm.1849-8558.2015.42.3001 } \\
\text { URL: } \underline{\text { http: } / / d x . d o i . o r g / 10.18775 / j i b r m .1849-} \\
\underline{8558.2015 .42 .3001}\end{array}$ & $\begin{array}{l}\text { The use of social media and digital marketing is nowadays becoming a strategic tool in terms of } \\
\text { building brand awareness and running a marketing campaign. Shifting from the era of conventional } \\
\text { or mass media, by using social media and digital marketing, the marketers can track brand's } \\
\text { competitors and have more measurable campaign results. The usage of having these online activities } \\
\text { is also to know about people's opinion about the product, building brand reputation, and most } \\
\text { importantly very targeted for the millennials. The study is descriptive in nature. The study used The } \\
\text { Hook Canvas Model in Marketing by Nir Eyal. The study objective is to investigate why social } \\
\text { media and digital marketing is significant to do branding and marketing activities lately, and what } \\
\text { are the proper steps for doing so. The description is based on the explanation of social media and } \\
\text { digital marketing usage, especially for Millenials era, explaining the steps of doing digital and online } \\
\text { campaign, while also describing The Hook Canvas Model by Nir Eyal for the latest social media } \\
\text { and digital marketing phenomenon. The data used in the study include interview, observation, and } \\
\text { library research. The data were analyzed in three stages, such as reduction, presentation, and } \\
\text { conclusion drawing. The results of the study show that social media and digital marketing campaign } \\
\text { are not only useful to create brand awareness and engage the customers but also crucial in terms of } \\
\text { measurement. By doing these kinds of marketing efforts (digitally), the effectiveness of each } \\
\text { campaign can be measured, the behavior of the customers or even the potential ones could be tracked } \\
\text { beforehand, and the reach of the message could be spread wider rather than making only traditional } \\
\text { marketing efforts. }\end{array}$ \\
\hline
\end{tabular}

\section{Introduction}

Millenials Generation is the term for people that born after 1981 and before 2002 (Blair, 2017). As a Marketing Manager for the consumer goods' brand, es pecially snacks that targeted to 15 to 18 years old teenagers (as per 2017, this target market means people who are born between 1999 and 2002), the decision of not using digital and social media marketing will be a big loss for the selling. These 'last millennials generation' were born with rapid internet and technology growth. In 1995-1996, Indonesians had Independent Dial-Up internet connection from home or the office, thanks to the commercial Internet Services Providers (ISPs), and also Warnet or Warung Internet - place to use internet - was a huge phenomenon back then, and after the tragedy of 1998's Political Reformation, the moment coincidentally also became the revolutionary moment of the internet and social networking for Indonesian (Lim, 2003). This means that 'the last millennials generation' who born after 1998 is the generation who lived their life with the ease of technology, internet, and for the quite lucky kids - gadgetfriendly since they were just kid. These 15 to 18 years old teenagers may not even watch the television anymore in 2017, as a matter of fact, the millennials in big cities nowadays tend to shift from television to over-the-top (OTT) services like Netflix or Hooq (Jakarta Globe, 2017) so that even strengthen the argument that conventional media nowadays are shifted to the digital. Forbes.com even stated that they have the Nielsen data which shows less than $2 \%$ millennials watching television as per June 2017 (Ehlers, 2017). These teenagers as our targeted consumers tend to spend most of their time with their smartphone and/or gadget to access social media, watching video, and some other entertainment.

\section{The Uses of Social Media and Digital Marketing}

Social media and digital marketing activities are very important, it's not only for gaining revenue, but also to reduce the cost of conventional marketing activities. It may be good if currently this company's sales numberstill good, but will it last? Will this brand become the top of mind brand for the next five years without being lost or overshadowed by the competitors? That is what social media and digital marketing useful for; we 
can predict the future, do prevention of crisis, and create innovations; because by using social media and digital marketing we can track our brand's competitors. The usage of having these online activities is also to know about people's opinion about our product, build our brand reputation, and to find the voices of our brand supporters or even the haters. These are things that conventional marketing hardly achieved effectively.

The big marketing budget that originally for traditional marketing activities can be shifted to activate the digital marketing strategies, because by going digital we can check how much the frequency of the customer that get our advertisement, how their buying and lifestyle behavior, etc.

First of all, TVCs Advertisement, Sales Promotion and Below The Line (BTL) may be good and usefulfor the past generation, the budget that will be spent on those marketing channels will be huge, yet the effectiveness by the revenues number may hard to checked in detail because the evaluation is not really measurable. Those channels cannot really do direct targeting. People who watch television, come to the store or come to the event may vary; they who watch or come may not our product's target market, and with those conventionalchannels we cannot track their database and their behavior. With digital and social media activities, we can track people's behavior and create a database for us. The advertisement can be targeted directly to the specific age, gender, location, and even their shopping lifestyle. Using digital, it eases us to know our consumers' profiles. Checking our competitor will be also easier than past marketing activities. We can check their new promotions on their website, what content they create to engage with their customers, what is their latest product development; all of these elements can be tracked using social media and digital tools.

Also, social media helps Marketers to reduce the marketing budget, placing advertisement on TV, Radio or even Printed Media need a huge budget, same goes with creating brand activation events. However, digital campaign through Facebook Ads, Instagram Ads, Youtube Ads, or even placing ads on millennials-friendly sites like Webtoon, Line or IDN Times, this will be 'low cost - high impact' marketing. Also, social media helps marketer to create more direct interaction with the consumers, because they can give direct feedback about our product in our social media, even now there are Instagram Polling and Youtube Polling that can help marketer to launch survey about our product via online and targeted to our public market - the millennial teenagers.

To advertise the product, digital channel could be used such as social media network, Email Marketing, and affiliate marketing. One of the Digital Doughnut Contributor stated on one article titled ' 4 Important Digital Marketing Channels You Should Know About', said that E-mail marketing is very effective to make us gain new customers or improving or strenghtening our relationships with the existing customers
(Digital Doughnut, 2014). With email marketing we can share the latest promo or blog stories of our product to our mail database, but this has weakness such as people will mark our newsletter as spam is we keep send repetitive contents. We can also do online affiliate marketing, it can make more exposure of our brand because we put advertisement in our affiliates' website, for our product we can do affiliate with Line Shop, Shopback, Lazada, Tokopedia and etc. while we get more coverage, the consumer will be redirected to our website and that can give us more traffic and database. What the affiliates will get are Pay Per Click (PPC), Pay Per Sale (PPS), or Pay Per Lead (PPL) (Digital Doughnut, 2014).

As quoted by democraticmedia.org, "Young people in particular rely on mobile devices for a growing number of services: phone, web and social network access, maps and directions, entertainment, and more" (Democratic Media, 2011), the young generation still rely on their mobile gadget to do several things, and one of them is for social network access. George Beall of Business 2 Community stated that Facebook is great for the width of marketing strategy, but for the depth connection to the younger generation, Instagram will be a good platform to achieve that (Beall, 2017). Teenagers are more likely to give attention to a video and visual content, this generation (sadly) is a short-attention span. Beall stated that Attention spans are about 8 seconds on average for adults and even shorter for teenagers (2017) so we as a marketer have to create the short yet effective content that grabs teenagers' attention and interesting enough to make them not skip our content. Based on this situation, the most suitable social media channel would be Instagram and Youtube. Millennials love visually attractive content and personal-related stories, instead of seeing text. Marketers should not just create massive promotion banner or video; instead, it is more useful to create an interesting story based on the product.

To give an example for seeing step by step process theoretically; A startup local brand wanted to launch new Energy Bar called MatchaBar, special energy bar with oat, green tea, and the flavors like the original (Matcha), Chocolate, and Berries. The strength of this product is not only this is a healthy and low-fat snacks, it can also give us natural antioxidant from the green tea that can make teenagers eat healthy but still delicious and easy to get in the urban cities for their daily snack. Since the target market is revealed which is Millennials, instead of doing heavy-promotion for this MatchaBar conventionally, the marketers could create social media campaign and hiring the Instagram influencers that have slim body, healthy lifestyle, and the most important is the influencers that gained massive attention by these teenagers nowadays. Co-partnerships with these influencers as the brand's buzzer and cooperate to create a campaign (for example "Rachel Vennya sharing \#SehatItuEnak story - consist of several posts that show how she can live her daily life and be productive without getting tired or snacking recklessly because she keeps consuming MatchaBar). As the MatchaBar marketer, 
it is possible to create this "story" episodically to make these teenagers engaged, this strategy can also be implemented in more detail story for Youtube video - that we will attach as Youtube ads on every video that 15 to 18 years old teenagers watch currently. The story needs to be relatable, exciting and educating the audiences/customers, so our content will be valued and that builds the trust to our brand.

Not only that, with Instagram nowadays many brands (especially online startup and e-commerce) are become very active on creating mini quiz contents; so in this kind of product it could be a quiz consist of gues sing mis sing picture or healthy trivia that can create teenagers' engagement in the post and that will help to subtly promoting our product, especially if the free product is given for the winners and since this is a new brand from our company, this can be really helps to increasing the brand and product awareness.

\section{Social Media and Digital as Marketing Strategy}

For an effective marketing strategy for teenagers, social media is vital. Stated by Starngage.com, right now Indonesia has around 100 million social media users, and if we look specifically for the marketing strategy of the younger generation, Instagram and Youtube are in the leading position that used by social media networks and Influencer Marketing because as the data stated, $50 \%$ of internet users in Indonesia are using Instagram (out of 48 million total of Indonesia Instagram Users). Another data also shows that $74 \%$ of consumers nowadays will depend on their social networks to guide the purchases (Starngage.com, 2017). This shows that the Indonesian young generations at this moment need social media to lead their feeling and decision of buying things. The most suitable social media channelfor the last millennials generation consumer will be Instagram and Youtube; and what about Facebook? Actually, we can also create Facebook Business Fan Page. By creating Facebook Fan Page, we can create targeted advertising; we can set the target of the age, demographics, economy, what gadget they use, and even their interests. Using 'pixels' on Facebook Business, it allows us to set the budget, see the potential reach, and track the conversion later. From Facebook Business we can also link the advertisement to be the Instagram Advertisement for Instagram users (we can set the contents at the same time by Facebook Business Ads).

There are five digital objectives why our brand need to be active in social media; which are 1) To create brand awareness, 2) To create database and engage with them, 3) To do customers retention and loyalty, 4) To do competitor check via online, and 5) To gain conversion for sales. These objectives can also see from the perspective of Nir Eyal's Hook Model:

\section{The hook canvas}

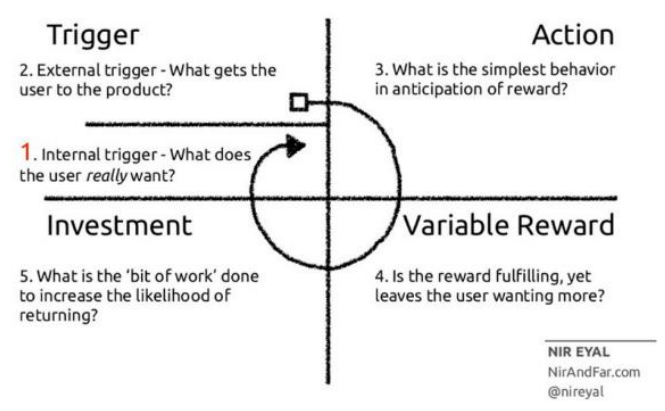

Figure 1: Nir Eyal's The Hook Canvas Model

\section{Source:}

http://www.meaningfulhq.com/images/hookCanvas.png

The objectives of going digital, marketers need to know what is the internal and external trigger of our product before we publish it, so we create the brand awareness strategy from the beginning, then we do action by creating interaction and engagement to our customers, this is can be used to gain their database and tracking their buying system/behavior. Then we give the variable rewards, give them loyalty program or do customers retention to maintain the customers for keep buying our product, and when all of the steps are done we get the investment, which is the sales conversion.

Conversion can be tracked and it is measurable, based on the objectives. To make measurement of all this, first of all, we need to set the Key Performance Index (KPI), especially in sales/conversion. By doing an online campaign, it will be much easier to measure that, for example through social media campaign, the measurement would be the total numbers of people who talk about our brand and interested with our product (see from the total number of the hashtags usage, or use social media measurement tools to see their interest of our product in social media conversation). We can break this down based on our objective. First, to measure the brand awareness, we can see the number of followers / fans of the official social media, how many view post, like and share posts; if we using Google Analytics or Clevertap tool we can see the rate month on month, and also we can measure by the reach of the social media (Facebook Business and InstagramBusiness have good analytic report for this). Second, to measure the engagement, according to Hanifa Aljufri as Digital Marketing Assistant Manager of Via.com Indonesia, we can measure the Engagement Rate by this formula: Call to Action (CTA) divided by the total audiences and multiply with $100 \%$ [CTA: Audience x 100\%], and she also stated that to measure the conversion, especially with Facebook Business, we can create and set one HTML for our website (for example, www.via.id/order_confirmed), the conversion will be measured when user bought the product from the website and finally arrived in that confirmed HTML; this will track the traffic of user who actually buys product in 
our website too (Aljufri, 2017). As the example, in Via.com Indonesia - travel company who runs both offline and online marketing strategy, Hanifa stated that the revenue attribution of digital activities is $69 \%$ and to measure the online campaigns, Via.com marketers use Universal Tracking Meters (UTM) as Source and combined with Google Analytics data to measure the traffic and conversion (Aljufri, 2017).

\section{Conclusion and Recommendation}

So for the startup or the latest product(s) in Indonesia, it is recommended to have Social Media Management Tools for scheduling and monitoring and/or Social Media Listening Tool to measure what people say about the brand and the product (for starters, it is suggested to use Hootsuite or Sproutsocial). After that, it is also important to check engagement in the analytics (or with that previous engagement rate formula), and also use Google Analytics. All these social media and digital marketing strategies may look complicated and quite hassle in the beginning, but then again if the segmentation or the target market is categorized as Millennials, these marketing efforts will be suitable to directly targeting them and all of this hard work will be paid off for the company at the end of the day.

\section{References}

- Aljufri, H. (2017, November 8). Digital Marketing Measurement. (S. Silvia, Interviewer)

- Beall, G. (2017, March 31). 8 Keys to Connecting With Teens on Social Media. Retrieved November 9, 2017, from Business 2 Community: https://www.business 2community.com/social-media/8keys-connecting-teens-social-media01807524\#77j03v2I3w35piry.97

- Blair, O. (2017, April 11). What Comes After Millenials? Meet The Generation Knows as Linkster. Retrieved November 9, 2017, from Indepedent.co.uk: http://www.independent.co.uk/life-style/millennialsgeneration-z-linksters-what-next-generation-x-babyboomers-internet-social-media-a7677001.ht ml

- Democratic Media. (2011, October). The New Age of Food Marketing. Retrieved November 9, 2017, from DemocraticMedia.org: https://www.democraticmedia.org/sites/default/files/field/p ublic/2017/digitalads_new_age_food_marketing.pdf

- Digital Doughnut.(2014, November 5). 4 Important Digital Marketing Channels You Should Know About. Retrieved November 9, 2017, from Digital Doughnut: https://www.digitaldoughnut.com/articles/2014/november/ 4-important-digital-market ing-channels-you-should

- Ehlers, K. (2017, June 27). May We Have Your Attention: Marketing To Millennials. Retrieved November 9, 2017, from Forbes: https://www.forbes.com/sites/yec/2017/06/27/may-wehave-your-attention-marketing-to-millennials/
- Jakarta Globe. (2017, November 4). Millennials to Decide Future of TV in Indonesia. Retrieved November 9, 2017, from Jakartaglobe.id: http://jakartaglobe.id/business/millenials -to-lead-changein-indonesia-tv-future/

- Lim, M. (2003, May 16). The Internet, Social Networks, and Reform in Indonesia. Retrieved November 9, 2017, from http://citeseerx.ist.psu.edu: http://cites eerx.ist.psu.edu/viewdoc/download?doi=10.1.1. $528.838 \&$ rep $=$ rep $1 \&$ type $=$ pdf

- Starngage.com. (2017, November 8). Influencer Marketing in Indonesia. Retrieved November 9, 2017, from Starngage.com: http://starngage.com/influencermarketing-indonesia/ 